\title{
The Drosophila Fos-related AP-1 protein is a developmentally regulated transcription factor
}

\author{
Karen K. Perkins, Arie Admon, Nipam Patel, and Robert Tjian \\ Howard Hughes Medical Institute, Department of Molecular and Cell Biology, Division of Biochemistry and Molecular \\ Biology, University of California, Berkeley, California 94720 USA
}

\begin{abstract}
Drosophila AP-1 consists of two proteins (dFRA and dJRA) that have functional and structural properties in common with mammalian Fos and Jun proto-oncogene products. Here, we report the isolation and characterization of cDNAs encoding the full-length IFRA and dJRA proteins. The predicted amino acid sequences reveal that both proteins contain a bipartite DNA-binding domain consisting of a leucine repeat and an adjacent basic region, which are characteristic of members of the AP-1 family. By using protein translated in vitro or expressed in Escherichia coli, we demonstrate that dFRA, in contrast to the mammalian cFos proteins, recognizes the AP-1 site on its own and activates transcription in vitro in the absence of dJRA or Jun.

Heteromeric complexes formed between AFRA and dJRA bind the AP-1 site better than either protein alone, and the two proteins activate transcription synergistically in vitro. In the developing embryo, dFRA mRNA is first expressed in a limited set of cells in the head and is later restricted to a subset of peripheral neurons, several epidermal cells near the muscle attachment sites, and a portion of the gut. In contrast, dJRA appears to be uniformly expressed at a low level in all cell types. These results indicate that dFRA is a developmentally regulated transcription factor and suggest that its potential interplay with dJRA plays an important role in celltype-specific transcription during Drosophila embryonic development.
\end{abstract}

[Key Words: Drosophila; transcription; AP-1]

Received January 26, 1990; revised version accepted February 28, 1990.

A knowledge of the normal functions of proto-oncogenes in cell growth and differentiation and the mechanisms by which they act are central to an understanding of oncogenesis. Drosophila has been particularly useful for discerning the normal roles of proto-oncogenes in development. A number of Drosophila proto-oncogene homologs, such as src, ras, erb-B, rel, and int-1, display cell-type-specific expression or have been shown to affect certain developmental stages. In some cases, a corresponding mutation in the gene has been isolated, enabling the unambiguous identification of the biological processes in which these proto-oncogenes are involved (for review, see Adamson 1987; Bender and Peifer 1987; Shilo 1987; Steward 1987; Bishop and Corces 1988; Schejter and Shilo 1989).

A wealth of evidence, accumulated from studies of a variety of organisms, indicates that the products of proto-oncogenes fulfill their biological functions by participating in different stages of signal transduction, thereby governing the ability of cells to respond to external cues. For example, many proto-oncogene products have been shown to transmit signals via protein phosphorylation and are either receptors, such as Erb-B, or membrane-associated cytoplasmic proteins, such as the src gene product. Some membrane-associated oncopro- teins, such as those of the Ras family, hydrolyze GTP, triggering a cascade of subsequent regulatory events. Other oncoproteins, such as Myc and Fos, are localized in the nucleus and have been implicated in gene regulation (Curran and Franza 1988; for review, see Hanley 1988).

The transient expression of Fos is one of the earliest known responses to numerous external stimuli, such as TPA, and serum and calcium ionophores, which activate distinct pathways in both differentiated and nondifferentiated cell types. In addition, Fos has been found to be associated with chromatin. These results originally suggested that Fos was a nuclear target for signal transduction whose transient induction triggered the expression of specific genes. The expression of Fos has also been observed in a spatially restricted fashion during mouse embryonic development and appears to be associated with differentiating tissues (for review, see Adamson 1987).

It had long been observed that cellular Fos was complexed with a protein designated $\mathrm{p} 39$ /Curran and Teich 1982). The findings that $\mathrm{p} 39$ is the Jun oncoprotein (Rauscher et al. 1988b) and that Jun is a member of the transcription factor AP-1 family (Bohmann et al. 1987) provided the first convincing link between signal trans- 
duction by proto-oncogene products and transcriptional activation. The mammalian AP-1 family is now known to consist of multiple proteins [such as Fos-related antigens (FRAs), FosB, JunB, and JunD (Ryder et al. 1989; Zerial et al. 1989 and references therein)] that are related to Fos and Jun by virtue of their recognition of the AP-1binding sequence, TGACTCA, which can also act as a TPA- and serum-inducible enhancer element (Lee et al. 1987).

It is likely that all members of the AP-1 family influence gene expression via their interactions with the AP-1 site. However, recent evidence indicates that Fos and mammalian Fos-related proteins must form heterodimeric complexes with Jun to recognize the AP-1 site. Their inability to bind the AP-1 site on their own has been attributed to the observation that they are not able to form homodimeric complexes, at least in vitro. Jun, however, can form a homodimeric complex and recognizes the AP-1 site on its own (Halazonetis et al. 1988; Rauscher et al. 1988a). The formation of these complexes is dependent on the integrity of the leucine repeat motifs that are structural features of both Fos and Jun proteins (Kouzarides and Ziff 1988; Landschulz et al. 1988; Gentz et al. 1989; Ransone et al. 1989; Turner and Tjian 1989).

There is no evidence thus far that Fos or Fos-related proteins can act directly as transcription factors in vitro, although transient transfection assays suggest that Fos and Jun together generally result in stronger activation of transcription than Jun alone (Chiu et al. 1988; Sassone-Corsi et al. 1988; Schønthal et al. 1988). Thus, Fos apparently plays an active role, directly or indirectly, in the transcription reaction, despite its inability to recognize the AP-1 site specifically. Because it is likely that the coordinated activity of the two proto-oncogenes plays a significant role in transcriptional activation, it is important to understand the mechanism by which they act. The most direct strategy for determining the mechanism of Fos activity is by reconstituting transcription in vitro by using purified protein. However, the purification of Fos has been problematic because the native mammalian Fos proteins do not recognize the AP-1 site.

Drosophila AP-1 consists of two proteins that are related to Fos and Jun by their biochemical properties (Perkins et al. 1988). These proteins have been designated Fos- and Jun-related antigens (dFRA and dJRA) because they cross-react with antibodies to Fos and Jun. As a first step toward biochemical and genetic characterization of these proto-oncogene products, we have cloned the genes encoding them and find that they possess structural motifs in common with their mammalian counterparts. Using protein expressed in Escherichia coli and purified subsequently by DNA affinity chromatography, we examined the transcriptional activation properties of the Drosophila Fos- and Jun-related proteins, singly and in combination. These studies reveal that dFRA, although structurally similar to Fos, participates in the transcription reaction by a unique mechanism of action. The presence of Fos- and Jun-related oncoproteins in the Drosophila embryo suggests that they may exhibit temporal or tissue-specific expression consistent with a role in embryonic development. We have therefore used in situ hybridization to analyze the spatial expression of these genes. Our results suggest that dFRA may play a role in the function or determination of a particular subset of cells in the developing embryo and that, in contrast to mammalian Fos, it is able to carry out its function either independently of or in conjunction with a Jun-related protein.

\section{Results}

Isolation of cDNAs encoding Drosophila AP-1 proteins

To study the biochemical properties of dFRA and dJRA and to determine their expression patterns in the developing embryo, we isolated the cDNAs encoding these proteins. Our initial attempts to isolate Fos and Jun relatives by cross-hybridization were unsuccessful. Therefore, we purified sufficient quantities of dFRA and dJRA proteins ( $\sim 3 \mu \mathrm{g}$ of each) from Drosophila embryos (750 grams) according to the purification scheme described previously (Perkins et al. 1988), and determined the sequences of several tryptic peptides (as described in Materials and methods). From this information, we designed oligonucleotides that were used to screen various cDNA and genomic libraries. By this approach, we obtained the full-length dFRA and dJRA cDNAs (Fig. 1A,B). A single dJRA cDNA was isolated from $\sim 700,000$ clones in a library prepared from embryos harvested between 9 and $12 \mathrm{hr}$ of development. To obtain the dFRA cDNA, we first isolated a fragment of the dJRA gene from a genomic library and then used this fragment to probe a cDNA library prepared from embryos between 3 and 12 hr of development (as described in Materials and methods).

The various Drosophila cDNAs were subcloned from phage $\lambda$ into Bluescript-SK to generate dFRA-SK and dJRA-SK, which were then sequenced (Fig. 1). Within the predicted amino acid sequences of IFRA and dJRA, the tryptic peptides obtained previously were identified (Fig. 1). The dFRA-SK cDNA is $3652 \mathrm{bp}$ in length and contains an open reading frame (ORF) of $1785 \mathrm{bp}$ that encodes a protein of 595 amino acids. The dJRA-SK cDNA is $1178 \mathrm{bp}$ in length and contains an ORF of 867 bp that encodes a protein of 289 amino acids.

By using the Drosophila AP-1 cDNAs as probes, we have localized the AFRA and DJRA genes to the regions $99 \mathrm{~B}(9-10)$ and $46 \mathrm{E}$, respectively, on polytene chromosomes (data not shown). Although, the $46 \mathrm{E}$ region has not been well characterized, the claret gene is within 99B; Yamamoto et al. 1989, and Southern blot analysis has demonstrated that this gene lies within $12 \mathrm{~kb}$ of dFRA (data not shown).

Both IFRA and dJRA proteins share structural features with their mammalian AP-1 counterparts. The sequence of dFRA resembles that of Fos, and the sequence of dJRA resembles that of Jun. For example, the Fos basic domain responsible for enhanced DNA binding of Fos-Jun complexes (Bohmann and Tiian 1989; Turner and Tiian 


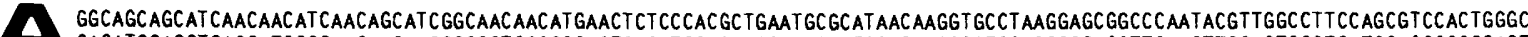
CAGATGCACCTCACCATGGCCAACAACAAGGCGGG GGGCCCACTCAGATCCAGGGCGTGCCCATCCAGACGCCCTCGACCGGCACCTT CAACTTCGACTCCCTGATGGACGGCGGCACT CGTAACGCCCGTCTCCGGACCCCTCGTCCCGAACAGC TCCTCCACGAACAAGCACCGCTGGAGCTGCCCACGCCCACCGCCCACTAGTGCTCTCCCCGTCGCCGCCGCGAGCCACGT TGG TIGGAGCGAGACAAAGAACCCCCGCCCCCCAAAGGAAATCCAGCCAACTTGT TGT TGTTACACT TGATTGTTTAACACTTT CACAAGTGCAAAGCCAGAACATTCC CAACAAACCGTCAA AAAACTGTGTGATATCTGCAATACAGCAACGC TTITTTCCGCAGAGCGGTAGAAATCCGTGGATAATTACGAAATATTCAACCTAAAGTCGT TCAAAGTTCGATAAACAACGGTG GTGG AGCGGGGCGTGGTTCGCCCGACTTTAATCTACAGAATTGACTGGAAAAGGCCAAAAAGGCGAAAAGAGAGTGTGTGTGTGTGTGCTCGTGTGCTGGTGTTTGATTGTGTGTGTGAGTGCC

AGCTGCACATGTAAGT TTIGTTTATAATCGCCAACTGGAGAGCAGCAACAATGAAAGTCAAAGTGGAGCGCACAACGAAAAAGCCCGCCATCAGAAAGCCCGAGGATCCAGATCCGGCGG

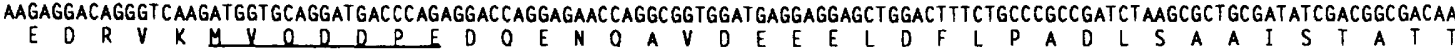

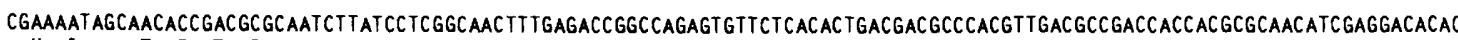
$K$ I $A$ A $T$ P $P$ T $R$ N $N$

TGGGCCACTTGCTCTCGGACACGCAGACCGATCGTGTGGC TGGTTGCGCGgGATTGCAGTGCCAAAGG TGCTACCCAATGCCATTGATGTCCTGGGCATGgGTATTCCCACCGGTGTTT

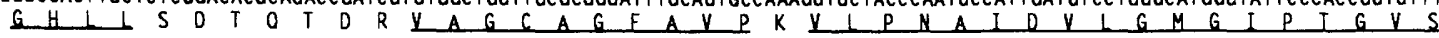
CGTCGCTCCCACTTCAGCAGACATTCGATITGAGCCTGGgGCAGgGCAGCGAGTCCGAGGACTCCAACGCTTCGTACAACGATACGCAGATGAaCGAGGaGCAGGACACGACCGATACTT

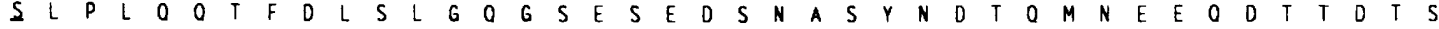
CAAGTGCCCATACGGACAGCACCTCGTACCAAGCTGGCCACATCATGGCGGGCAGCGTGAACGGCGGCGGTGTCAACAACTTCTCCAATGTCCTGGCCGCCGTGAGCTCTAGCCGCGGAT $S$ A H T D S T S Y O A G H I M A G S V NGGG V N N F S N V L A A V S S S R G S CGGCGTCGGTGGGCAGCAGCAACGCGAATACCTCAAATACGCCGGCTCGTCGTGGCGGCGGCAGACGCCCCAACCGGTCGACGAACATGACCCCGGAGGAGGAGCAGAAGCGGGCCGTGC A S S V G $S$ S S S N A GCCGGGAGCGGAACAAACAGGCGGCGGCCCGTTGCCGCAAGAGGCGCGTGGACCAGACCAACGAGCTCACCGAGGAGGTGGAGCAGCTGGAGAAGCGgGGCGAGAGCATGCGCAAGGAGA

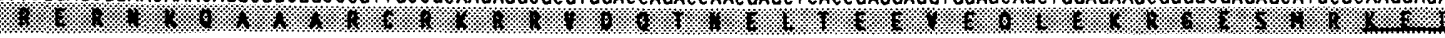
TCGAGGTGCTGACGAATAGCAAGAATCAGCTGGAGTACCTTCTGGCCACCCACCGGGCCACCTGCCAAAAGATTCGCTCCGACATGCTGAGCGTGGTCACCTGCAACGgTCTGATTGCCC 1. CGGCCGGACTCCTGAGTGCCGGGAGCAGCGGCAGCGGCGCGAGCAGCCACCACAACCACAACAGCAACGACAGCAGCAACGGCACGATCACCGGCATGgACGCCACGCTGACTCCACCG A G L L S A G S S GSG ASS H H N H N S N D S S NG T I T G M D A T L N S T G

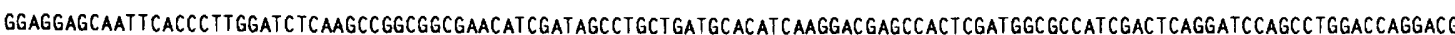

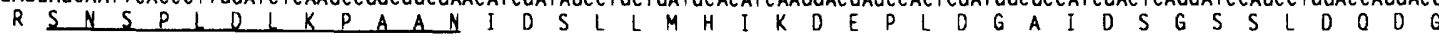
GTCCGCCGCCCAGCAAGCGCATCACCTTGCCGCCCATGTCCACGATGCCGCACGTTCACTTGTCCACGATATTAACGCCAACCGGGCCCTCGTCGgGATCTCTGCAGACGCCGATCACG

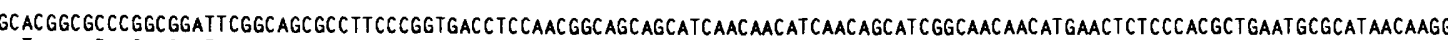
$T A P G G F G S A F P V T S N G S S I N$ S I N S I G N N M N S P T L N A H N K V TGCCTAAGGAGCGGCCCAATACGTTGGCCTTCCAGCGTCCACTGgGCCAGATGCACCTCACCATGGCCAACAACAAGGCGgGTGGGCCCACTCAGATCCAGgGCGTGCCCATCCAGACGC

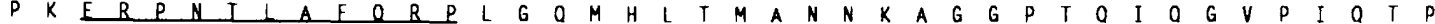
CCTCGACCGGCACCTTCAACTICGACTCCCTGATGGACGGCGGCACTGGGCTAACGCCCGTCTCCGGACCCCTCGICCCGAACAGCTCCTCCACGAACAAGCACCCGC TGGAGCTGCCCA $S T G T F N F$ D S L M D G G T G L T P V S G P L V P N S S S T N K H P L E L P T

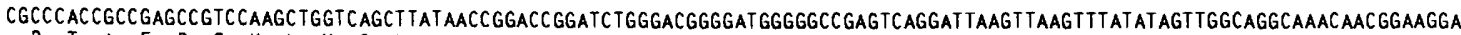
$P$ T A E P S K Y Y S L

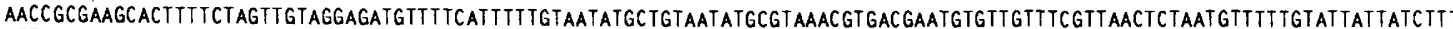
ATTATGG TTAATTTATGATTICGCTATGTCTTT TACATACGCCGAGGAGCTATGTACATATGTTATGTACTTGT AATTTGTGCAATTT TCAACCTCTTCATTGCGCGTTGTATATTTTC aAAAAATAT AaGAaCGCGAACGCGAACGCGAACGACCGACGATGCATGATGAGAATGATAAGGATAATGATGATAATAGGGCGTGTAGATTTGCAGGATGCGTTGTGATATTTATTATAA AaCGAATACAAAAGATGCGAGgAT GAAACAAAGTAGAAAGCAAACAGgAGCGTCTAATGAAAGGAACTAAGCCGGT TTTAAAATTGTACATTTAAACGAATCGTAAAGCGTAATATAC

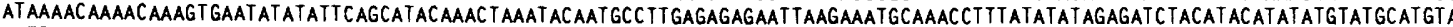
CATT TAAAGCTAAACAATAATGGCGTTGAaGCGAGTTTTATATTGAGCAAAAGCAAATG GAAATGAGATAAATATACTTATIGTGTACTCTGTAAGC TGCAGTAGAAACCCAAATATAT TTTTACTAAACGCAACATTGCGCTAT TTICAAATACCATTTATAAGAAATGACAAAAGCAAAGCAATTATITAATATGTAATTATG TATIIATGTATACCTATATCTACCTACCCACAACC TIAAATCAAAAAACCCAAAACGATTCAACAAAGC TGATCAGG TAAAGCAACTCTCGCCAGTTTCCACACT TAATTCTCAGAATATTCAAAATTTT TAATC TATACAAAACCAAACCGATT GATAGCAAATAAATGCACTTATAAGGGCAGAAAAACACCAAAATTTAAACCG 3652

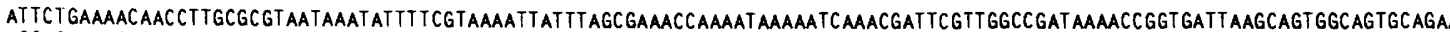

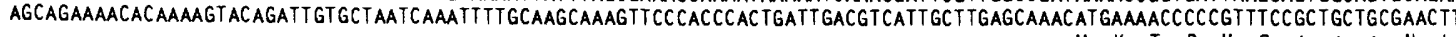
$M K T$ Y Y S A A A N L

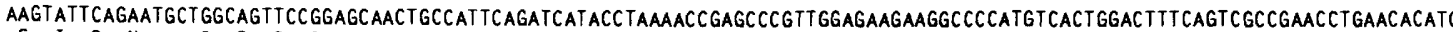

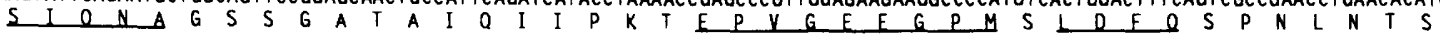

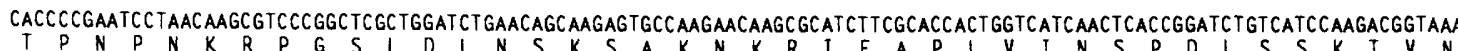

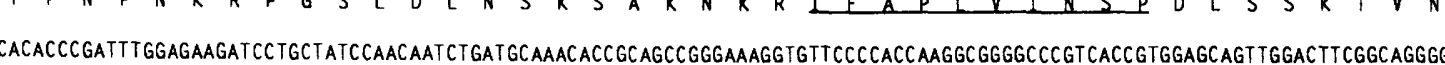

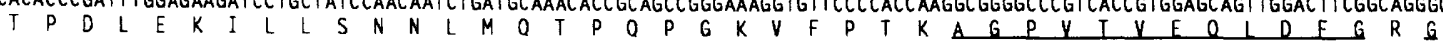

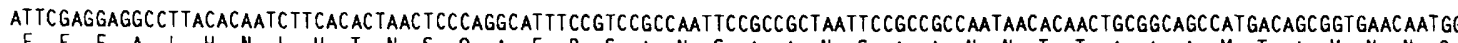
E E E A H N H H T N S OA F P S A N S A A N S A A N N T T A A A M T A N N N G

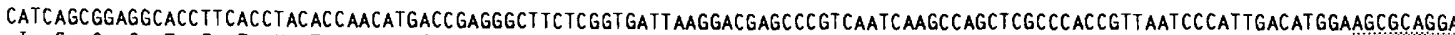

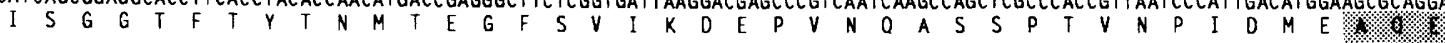
GAAGATCAAGCTGGAGCGCAAGAGGCAGCGTAACCGTGTGGCTGCATCCAAGTGCCGCAAGCGCAAGCTGGAGCGCATCTCAAAGC TGGAGGATCGCGTGAAGGTACTTAAGGGCGAGAA

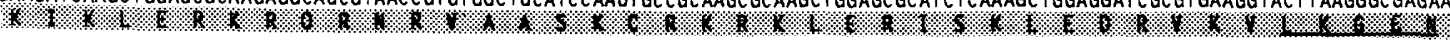

CGTGGACCTGGCTAGCATCGTGAAGAACCTCAAGGACCATGTGGCGCAGCTGAAGCAGCAGgTGATGGAGCACATTGCCGCGGGCTGCACGGTGCCGCCGAACTCGACAGACCAATAACA

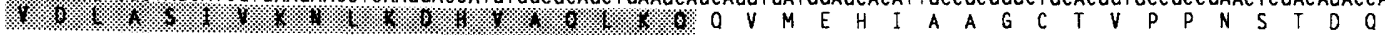

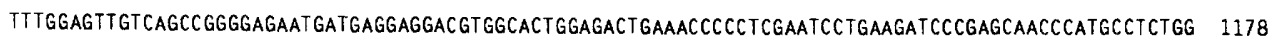

120 240 360 480 600 720
840 960

Figure 1. (Continued on facing page.) 


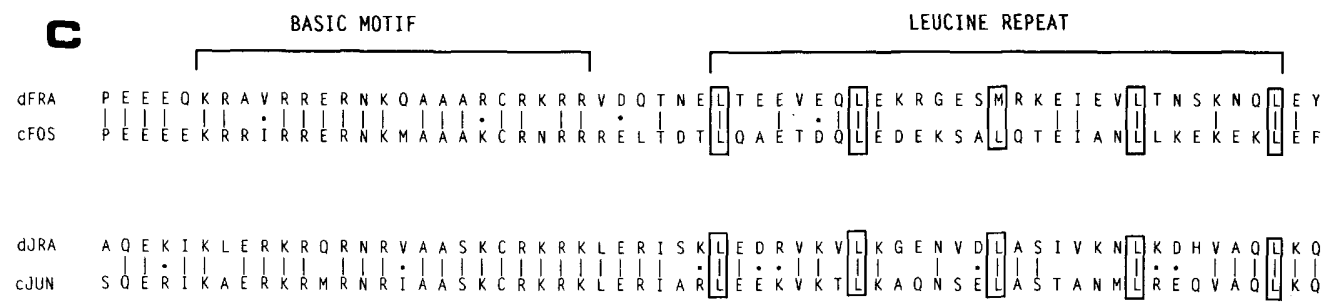

Figure 1. DNA and amino acid sequences of dFRA and dJRA. The nucleotide sequences of the cDNAs and the amino acid sequences of the ORFs of dFRA $(A)$ and dJRA $(B)$ are shown. The underlined sequences correspond to the peptide sequences obtained by trypsin digestion of dFRA and dJRA. The shaded regions represent the basic motifs and leucine repeats within dFRA and dJRA ORFs. (C) The basic motifs and leucine repeats of dFRA and IJRA are compared with those of Fos and Jun, respectively. The amino acids in boxes comprise the leucine repeat. Lines connect the amino acids that are identical between the proteins, dots represent conserved amino acids.

1989 ) is $79 \%$ conserved in dFRA. The corresponding domain of Jun is $89 \%$ conserved in dJRA (Fig. 1C). Furthermore, the Drosophila AP-1 proteins also contain a leucine repeat (Fig. 1C; Landschulz et al. 1988) that is present in Fos and Jun and is required for formation of the Jun homodimer and the Fos-Jun heterodimer (Bohmann and Tjian 1989; Turner and Tjian 1989|. The dFRA leucine repeat differs from that of Fos, however, in that a methionine residue replaces the third leucine. It has been suggested that methionine at this position would not significantly alter the structural integrity of the leucine zipper (Landschulz et al. 1988).

Another structural feature in common between the Drosophila and mammalian AP-1 proteins is the relative positions of the basic motif and adjacent leucine repeat within the protein molecule. As in Fos, these structural features are present in the middle of dFRA, whereas they are at the carboxyl terminus in dJRA and Jun (Fig. 1A,B). Interestingly, the Drosophila and mammalian AP-1 proteins have few significant sequences in common within the remaining portions of the proteins. The sequences of dFRA and dJRA cDNAs and their homologies with mammalian Fos and Jun sequences, respectively, within the basic motifs and leucine repeats provide strong evidence that the cDNAs we have obtained encode Drosophila AP-1 proteins.

dFRA and IJRA expressed in E. coli each recognize the AP-1 site

We demonstrated previously that DFRA and dJRA purified from embryo extracts were $\sim 70$ and $40 \mathrm{kD}$, respectively (Fig. 2A, lane 2) and that they each recognized the AP-1 site (Perkins et al. 1988). To verify that the dFRA and dJRA cDNAs that we isolated encoded Drosophila AP-1 proteins, it was essential to determine that the encoded proteins possessed similar biochemical properties. Toward this aim, dFRA and dJRA proteins were produced by using an $E$. coli expression system and were purified by DEAE-Sepharose and sequence-specific DNA affinity chromatography (as described in Materials and methods). The resulting fractions, as analyzed by SDS-PAGE, revealed that dFRA and dJRA had been purified to near homogeneity and were the same sizes as the
dAP-1 proteins purified from Drosophila embryos (Fig. $2 \mathrm{~A}$, lanes 2,5 , and 6). We have verified by Western blot analysis that purified dFRA and dJRA from bacteria cross-react with antibodies to mammalian Fos and Jun (data not shown; Perkins et al. 1988).

We next showed that dFRA and IJRA proteins purified from $E$. coli were capable of specifically recognizing the AP-1-binding site in a DNase I footprinting assay (Fig. 2B). It was necessary to add approximately fourfold more dFRA protein than IJRA protein to the binding assay to observe a footprint. In testing the individual proteins for DNA binding, we found that the DNase I hypersensitive sites resulting from the binding of dFRA are distinct from those of dJRA (see arrows, Fig. 2B). As expected, the hypersensitive sites resulting from dAP-l purified from Drosophila embryos, which contain a mixture of dFRA and dJRA, represent the sum of the hypersensitive sites from either of these two proteins alone. These results confirm that the Drosophila Fos-related protein, unlike cFos from mammalian cells, is fully capable of recognizing the AP-1 site on its own, albeit with somewhat lower avidity than dJRA (Perkins et al. 1988).

\section{Complex formation between $I F R A$ and dIRA}

Although mammalian Fos has not been demonstrated to recognize the AP-1 site on its own, it does form a heterodimeric complex with Jun that is dependent on the integrity of the leucine repeat domain (Turner and Tjian 1989). In addition, the Fos-Jun heterodimer has a higher affinity for the AP-1 site than Jun alone (Rauscher et al. 1988a; Zerial et al. 1989). Because we found that the Drosophila AP-1 proteins contained leucine repeats, it was of interest to determine whether they were capable of recognizing the AP-1 site as an oligomeric complex.

For this purpose, we employed an electrophoretic mobility-shift assay (EMSA), which can distinguish different protein complexes bound to DNA. AFRA and dJRA proteins were synthesized in vitro, separately or together, using a rabbit reticulocyte lysate. The products of the translation reaction were determined to be the proper size and to be of roughly equimolar concentrations by SDS-PAGE (data not shown). These in vitrosynthesized proteins were incubated with a labeled oli- 
A.

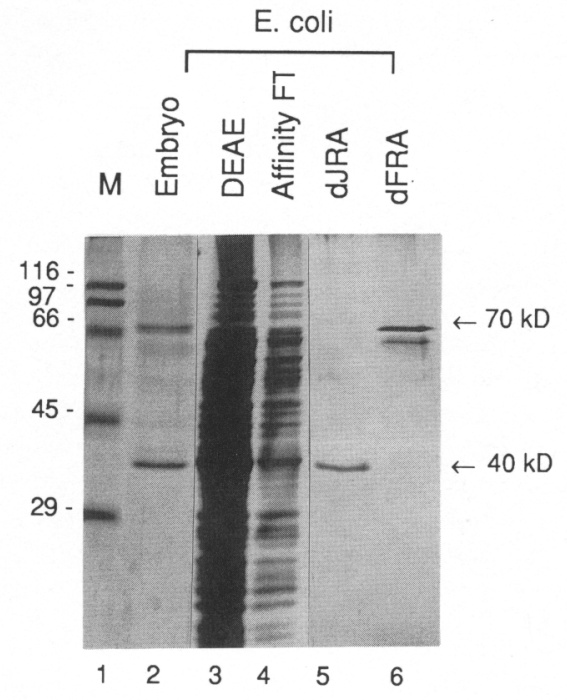

B.
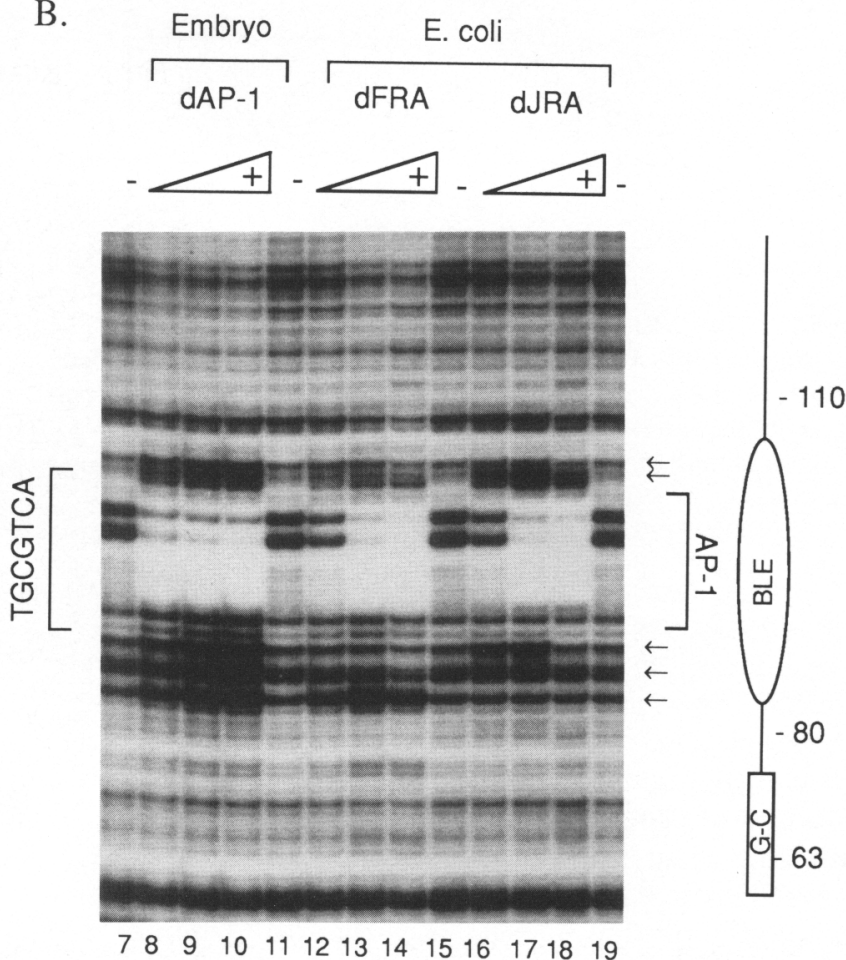

Figure 2. Purification and DNA binding of dFRA and dJRA expressed in E. coli. (A) Protein fractions from various stages of the purification were subjected to $10 \%$ SDS-PAGE and visualized by silver staining. (Lane 1) Molecular weight standards (M); (lane 2) dAP-1, purified from embryo extracts $(0.2 \mu \mathrm{g}$ of protein); (lane 3) DEAE flowthrough (FT, affinity column load, $\sim 5 \mu \mathrm{g}$ of protein); (lane 4) affinity FT $(\sim 1 \mu \mathrm{g}$ of protein); (lane 5$)$ dJRA affinity column eluate $(\sim 150 \mathrm{ng}$ of protein); (lane 6$)$ dFRA affinity column eluate $\sim 50$ $\mathrm{ng}$ of protein). (B) DNase I footprinting reactions were carried out as described previously and contained a probe spanning the human metallothionein IIA (hMTIIA) promoter that contains an AP-1 site (Perkins et al. 1988). Protein was added where indicated. (Lanes 8-10) dAP-1 purified from embryo (1.0, 2.0, and $3.0 \mathrm{ng}$ of protein, respectively); (lanes 12-14) dFRA purified from $E$. coli (2.5, 12.5, and $25 \mathrm{ng}$ of protein, respectively); (lanes 16-19) dJRA purified from E. coli $(0.3,3.0$, and $6.0 \mathrm{ng}$ of protein.)

gonucleotide containing an AP-1 site, and the resulting protein-DNA complexes were separated by PAGE (see Materials and methods|. We found that the combination of DFRA and dJRA is capable of forming a complex with AP-1 site DNA that has an electrophoretic mobility distinct from the complex formed either by dFRA or dJRA alone (Fig. 3). Although these experiments were carried out using dFRA and dJRA that had been cotranslated, we have evidence that cotranslation is not a requirement for formation of the dFRA-dJRA-DNA complex (data not shown).

The complex formed using the mixture of dFRA and dJRA appears to have a higher affinity for the AP-1 site than either dAP-1 protein alone, as judged by the relative amount of labeled oligonucleotide retained as the slower migrating species. In addition, the intensity of the band corresponding to the protein-DNA complex formed by dFRA is typically weaker than that formed by dJRA (Fig. 3 , cf. lanes 1 and 4 with 2 and 7). From other studies with EMSA, we have evidence that the complex generated by the binding of dFRA to the AP- 1 site is more stable at temperatures below $25^{\circ} \mathrm{C}$ (data not shown). These results strengthen our conclusions from DNase I footprinting data (Fig. 2B) that dFRA binds less strongly to the AP-1 site than dJRA does. Moreover, our findings indicate that DFRA and dJRA, like their mammalian counterparts, can form a heteromeric complex with enhanced DNA binding affinity.

\section{dFRA is a transcription factor}

We reported previously that dJRA, but not dFRA, activated transcription in vitro and suggested that dFRA may have been inactive due to the denaturing conditions required to purify this protein from the Drosophila embryo (Perkins et al. 1988). Here, we have used dFRA and dIRA proteins, purified by sequence-specific DNA affinity chromatography from $E$. coli harboring the appropriate expression plasmids, to test their transcriptional properties, singly and in combination. For these experiments, dFRA and/or dJRA were incubated with an extract prepared from Drosophila embryos that had been depleted of dAP-1 proteins by use of an AP-1 site-specific DNA affinity resin (Perkins et al. 1988). In the presence of a template containing four AP-1 sites, dFRA, on its own, activates transcription ( sevenfold; Fig. 4, lane 3). As expected, dJRA activates transcription to a similar extent (Fig. 4, lane 5). Furthermore, the combination of 

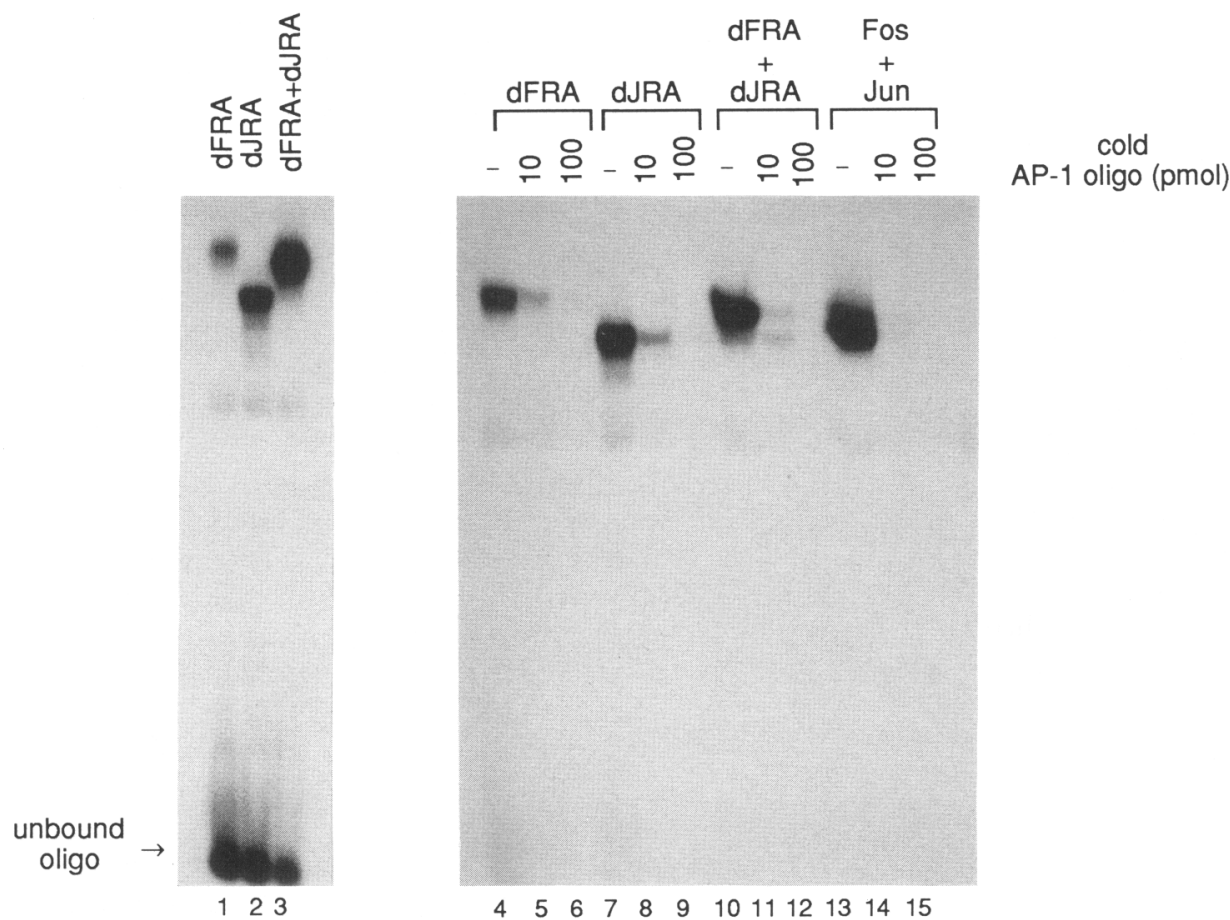

Figure 3. Protein-DNA complexes formed by dFRA and dJRA. In vitro transcription and translation and DNA-binding assays were as described (see Materials and methods; Turner and Tiian 1989). (Lanes 1-15) Various combinations of dAP-1 or human AP-1 proteins translated in vitro, as indicated, (lane 16) control: DNA-binding reaction carried out in the absence of in vitro-translated protein. The ${ }^{32} \mathrm{P}$-labeled and unlabeled oligonucleotides used were identical. They were blunt-ended, double-stranded, and contained the AP-1 site (top-strand sequence: 5'-GAGCCGCAAGTGACTCAGCGCGGGGCGTGTGCAGG-3') from the hMTIIA promoter (see Turner and Tjian 1989).

dFRA and dIRA activates transcription to a level greater than the sum of either of the two factors alone, because the mixture of half the amount of each dAP-1 protein resulted in an $\sim 20$-fold stimulation of transcription (Fig. 4 , lanes 7 and 8). No detectable activation was observed from a template that lacks AP-1 sites (Fig. 4, lanes 2, 3, and 6). In the absence of added dAP-1 proteins, these sites did not alter the rate of transcription in the depleted extract (Fig. 4, lanes 1 and 2). These results indicate that a Fos-related protein, dFRA, can act as a transcription factor on its own but can also function synergistically with a Jun-related protein, dJRA, to enhance transcription.

dFRA is expressed in a temporally dynamic and spatially restricted pattern during embryogenesis

As a first step toward studying the roles of dFRA and dJRA in Drosophila development, we monitored the expression of mRNA at various stages of embryogenesis. By using Northern blot analysis, we find that the temporal pattern of dFRA mRNA changes dramatically during embryonic development (Fig. 5). It is undetectable until $4 \mathrm{hr}$ after fertilization (Fig. 5, lanes 1 and 2), and present at increasingly higher levels between 4 and $12 \mathrm{hr}$ (Fig. 5, lanes 3 and 4). This high level of expression is then maintained between 12 and $16 \mathrm{hr}$ of embryo- genesis (Fig. 5, lane 5). In contrast, dJRA is expressed at a relatively constant level at all stages of development (data not shown). We estimate that the maximal levels of AFRA and dJRA expression are one-twentieth that of actin. Also, from the Northern blot, we calculate that the lengths of dFRA and dJRA mRNAs are $\sim 3.7$ and 1.7 $\mathrm{kb}$, respectively. These results suggest that the dFRA cDNA may contain sequences that are very near to the $5^{\prime}$ end of the message.

To study the spatial pattern of dFRA and dJRA expression in the Drosophila embryo, we used in situ hybridization with both radioactive $\left({ }^{35}\right.$ S-labeled RNA) and nonradioactive (digoxigenin-labeled single-stranded DNA) probes (see Materials and methods). By using in situ hybridization, we found that dFRA mRNA expression is restricted to specific cell types and tissues in the developing embryo. For example, RNA is initially expressed within cells of the head soon after gastrulation at 4-5 hr of embryogenesis (Fig. $6 \mathrm{~A}-\mathrm{C}$ ). The cells expressing dFRA in the head are likely to be mesodermal (Fig. 6B), and some of this expression is localized to a region surrounding the cephalic furrow (Fig. 6C). This head-specific expression was observed as late as $8 \mathrm{hr}$ of embryogenesis. During these early stages, dFRA mRNA expression is also observed in the dorsal ectoderm and amnioserosa (data not shown).

Later, in embryos that are older than $11 \mathrm{hr}$, dFRA ex- 


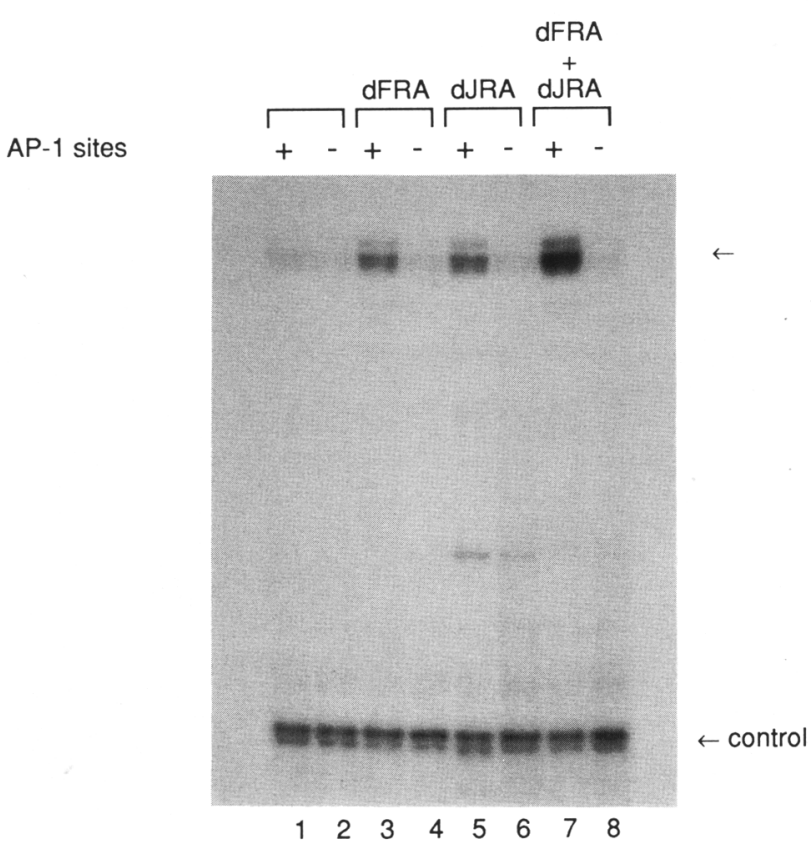

Figure 4. In vitro transcription with dFRA and dJRA expressed in E. coli. Transcription reactions $(25 \mu l)$ were carried out as described (Perkins et al. 1988). They contained either AP-1 CAT (chloramphenicol acetyltransferase) supercoiled DNA 10.2 $\mu \mathrm{g}$, lanes $1,3,5,7)$ or pMCAT supercoiled DNA $(0.2 \mu \mathrm{g}$, lanes 2, $4,6,8)$, Drosophila embryo extract (150 $\mu \mathrm{g}$ of protein) that had been depleted of AP-1 by use of a sequence-specific DNA affinity resin (Perkins et al. 1988), and alcohol dehydrogenase (Adh) proximal promoter DNA $(30 \mathrm{ng}, \mathrm{pHpHL}$; described in $\mathrm{He}$ berlein et al. 1985; Perkins et al. 1988) as an internal control. This Adh promoter fragment is transcribed at a basal level and does not respond to promoter selective factors. Reactions also contained approximate levels of dFRA [(lanes 5 and 6) $62 \mathrm{ng}$ of protein, (lanes 7 and 8$) 31 \mathrm{ng}$ of protein] or dJRA [(lanes 5 and 6) $94 \mathrm{ng}$ of protein; (lanes 7 and 8) $47 \mathrm{ng}$ of protein). The levels of transcriptional activation were quantitated by densitometric scanning.

pression is restricted to a subset of cells that appear to be part of the peripheral nervous system (PNS; Fig. 6D,F). In an effort to identify the cell types expressing dFRA more accurately, we excised the PNS from the embryo (Fig. 6F). From examination of the excised tissue in the abdominal segments, the dFRA-expressing neurons appear to be located near the lateral chordotonal cells and might be the es (extrasensory) or nd (numerous dendrite) neurons (Ghysen et al. 1986). At the same stages of development, dFRA mRNA is localized to a portion of the ectoderm that corresponds with muscle attachment sites (Fig. 6E). It is also observed in part of the mid- and hindgut and in the anal pad (Fig. 6G). Thus, the expression of dFRA is localized to specific cells of the Drosophila embryo. In contrast, dJRA is expressed uniformly at a low level in all cell types (data not shown). These results indicate that dFRA mRNA is localized to cell types of the embryo that are involved in the development of the head and nervous system.

\section{Discussion \\ Expression of a Fos-related gene in the developing embryo}

Many proto-oncogenes play a role in embryonic development and are expressed in a tissue- or stage-specific fashion (Adamson 1987). The detection of AP-1 in Drosophila embryo extracts (Perkins et al. 1988) provided a starting point for studying the role of Fos- and Jun-related proteins in an organism whose development is well characterized. By using in situ hybridization, we have now charted the expression of the Drosophila AP-1 mRNA in particular cell types during development. We find that dFRA mRNA is expressed in a spatially restricted fashion in specific regions of the head (between 4 and $8 \mathrm{hr}$ ) and PNS (between 11 and $13 \mathrm{hr}$ ). The precise identities that we assigned to individual cell types of the nervous system are tentative and will require double-labeling experiments to align the patterns generated with dFRA antibodies with the patterns seen with antibodies that label all or subsets of peripheral neurons (Bodmer et
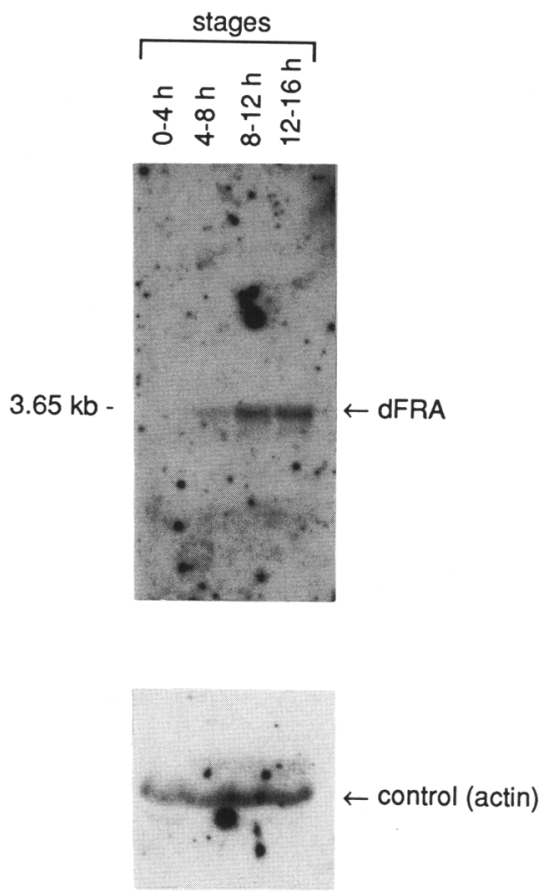

Figure 5. Northern blot analysis of dFRA mRNA expression. A Northern blot with RNA from various stages of Drosophila embryogenesis is shown. The Northern blot analysis was carried out as described (Hauser et al. 1985; Dynlacht et al. 1989). The probe used for hybridization was a restriction fragment of the dFRA cDNA that lacked sequences of the pBluescript vector and was internally labeled by nick-translation in the presence of $\left[\alpha^{-32} \mathrm{P}\right] \mathrm{dCTP}$. Following a $21-\mathrm{hr}$ autoradiographic exposure at $-70^{\circ} \mathrm{C}$ with an intensifying screen, the blot was stripped and then hybridized a second time with an actin probe, as described (Dynlacht et al. 1989). The length of autoradiographic exposure with the actin probe was $\sim 1 \mathrm{hr}$ under the conditions described for dFRA. Size standards were $0.24-9.5 \mathrm{~kb}$ (data not shown). 
al. 1987; Patel et al. 1989|. Interestingly, dFRA mRNA was not detected by in situ hybridization at stages of embryogenesis between $\sim 8$ and $11 \mathrm{hr}$. Because we ob- serve AFRA mRNA by Northern analysis, it is possible that dFRA mRNA is expressed during these stages at a low level in all cell types. In addition, dJRA mRNA was
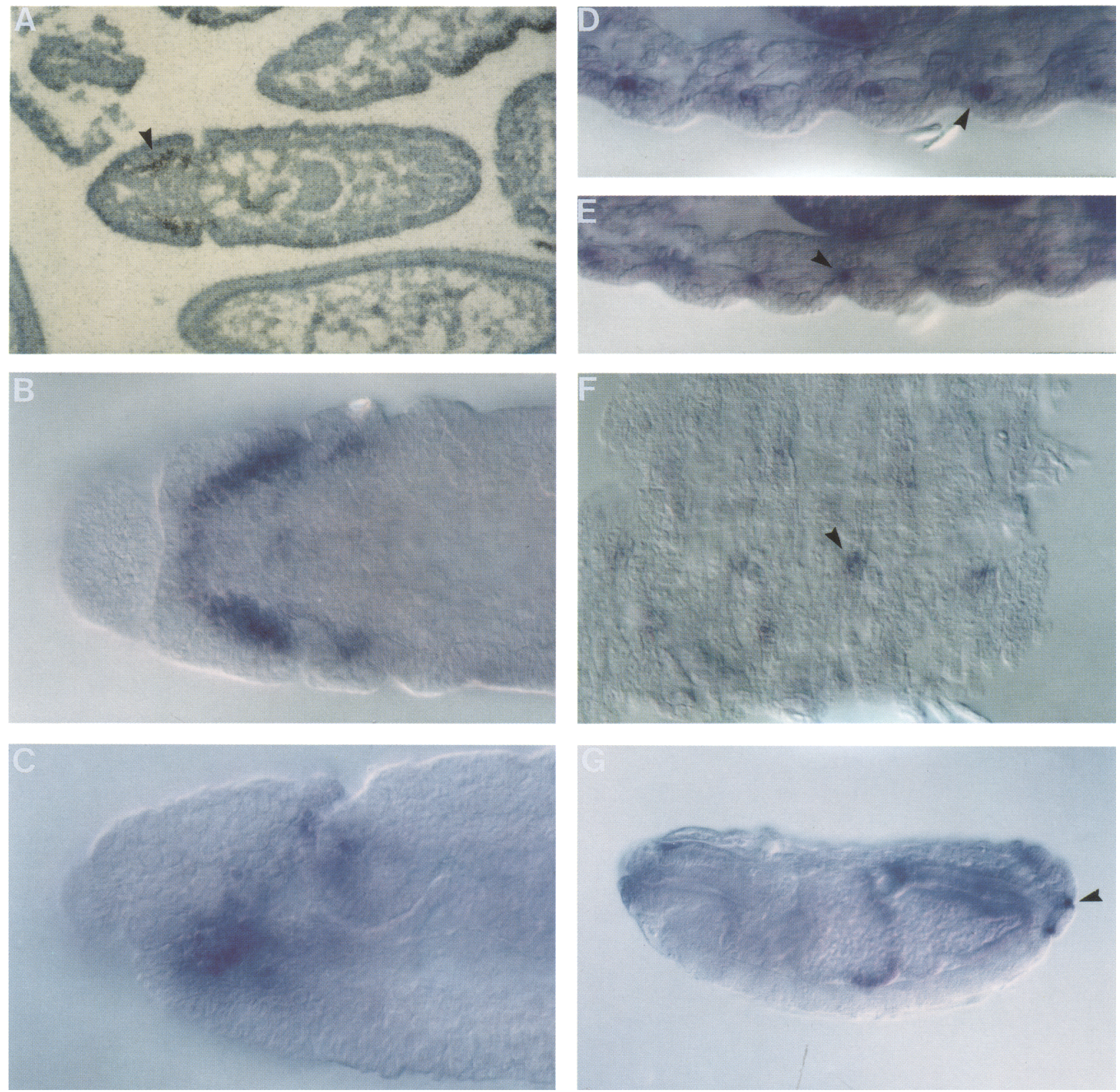

Figure 6. In situ hybridization analysis of dFRA expression in embryos. In situ hybridization with both radioactive and nonradioactive probes at different stages of embryogenesis. (A) Horizontal section of a Drosophila embryo (4-5 hr of development) hybridized with an $\left[\alpha^{-35}\right.$ S $]$ UTP-labeled RNA probe. The probe was prepared from dFRA-SK by use of T7 RNA polymerase and conditions described by Dynlacht et al. (1989). Whole-mount embryos $(B-E$ and $G)$ and tissue excised from a whole-mount embryo $(F)$ were labeled by hybridization with a nonradioactive single-stranded DNA probe. $(B$ and $C)$ Embryos between 4 and 5 hr of development. dFRA is expressed in the head in cells that we believe to be mesodermal. Embryos $(D-G)$ or tissue from embryos $(F)$ between 11 and 13 hr of development is shown. $(D$ and $F)$ Arrows indicate expression in cells that we believe to be peripheral neurons. $(F)$ Tissue shown is epidermis and PNS excised from an 11- to 13-hr embryo. (E) Arrow indicates cells that hybridize to a dFRA probe, which are located at muscle attachment sites. It appears that these cells are epidermal. $(G)$ Arrow indicates expression in the anal pad of an 11-to 13-hr embryo. Expression is also observed in cells of the midgut and hindgut. The orientation in each panel is as follows: $(B, D$, and $E)$ ventral views; $(C$ and $G)$ anterior left and dorsal up; the tissue $(F)$ is ventral up. 
detectable at levels of expression that were barely above background (data not shown), and we conclude that dJRA is expressed ubiquitously throughout the embryo. This is in marked contrast to the tissue-specific expression of the c-jun and junB genes during organ development in the mouse embryo (Wilkinson et al. 1989) and may reflect the involvement of mouse and Drosophila Jun proteins in distinct biological processes.

The finding that the expression of dFRA is spatially restricted is intriguing in light of the cell- and tissue-specific expression of mammalian cFos. For example, in the mouse embryo, Fos expression is restricted to extraembryonal tissues, such as the amnion and yolk sac (Deschamps et al. 1985 and references therein). In addition, a low level of Fos mRNA and protein is normally present in neuronal subpopulations of the adult rat brain and has been found to increase following exposure to a drug that induces seizures (Morgan et al. 1987; Saffen et al. 1988). Obviously, it is premature to assign a function for AFRA on the basis of its expression pattern. It is possible, however, that the expression of dFRA mRNA in the embryo reflects a role for dFRA in the expression of genes required for neurogenesis or for other developmental processes. A careful analysis of Drosophila embryos that possess mutated versions of the dFRA gene, as well as identification of the target genes for dFRA transcriptional activation, will provide additional information concerning the role of the fos-related proto-oncogene in Drosophila development.

\section{Synergistic activation by $d F R A$ and $I J R A$}

A number of investigators have reported a cooperative interaction between Fos and Jun that has been observed by DNA-binding experiments using proteins translated in vitro (Halazonetis et al. 1988; Kouzarides and Ziff 1988; Nakabeppu et al. 1988; Rauscher et al. 1988a; Schuermann et al. 1989; Turner and Tjian 1989) or by transient transfection assays (Chiu et al. 1988; SassoneCorsi et al. 1988; Schønthal et al. 1988). However, no direct in vitro evidence with purified Jun and Fos proteins has been forthcoming. We demonstrate that an in vitro transcription assay is feasible with purified Fosand Jun-related proteins from Drosophila. We present new evidence that a protein related to Fos can activate transcription autonomously. Thus, dFRA is a novel member of the AP-1 family that resembles Fos structurally but whose mechanism of action is different from that of Fos.

Our results also indicate that the mixture of dFRA and dJRA forms a more stable protein-DNA complex and activates transcription to a greater extent than either of the proteins alone. These experiments provide the first direct evidence that Fos- and Jun-related proteins can activate transcription synergistically. One simple explanation for the observed synergy is that the dFRA-dIRA complex is bound more stably to the AP-1 site than either of the two proteins alone. Indeed, our EMSA results would support this model. However, it is risky to make a comparison between our in vitro transcription assay and the DNA-binding reaction, because the in vitro transcription reaction contains additional proteins, such as general transcription factors, that may contribute to the transcriptional synergism in vitro. Another possibility is that IFRA and dJRA proteins possess specific amino acid sequences that contribute to the synergistic activation. The fact that dFRA may act on its own or in combination with dJRA provides an additional level of regulation of gene expression in the developing organism.

\section{dFRA is a relative of Fos}

The amino acid sequences of the basic region and leucine repeat of dFRA are more like Fos than Jun. We find, however, that dFRA is mechanistically more like Jun than Fos in its transcriptional activation and DNAbinding properties. These unexpected results raise questions about the structural features of dFRA that enable it to recognize the AP-1 site and activate transcription on its own where Fos cannot. A number of studies have demonstrated that the leucine repeats confer the dimerization function and that dimerization is a prerequisite for DNA binding. Thus, the fact that Fos cannot recognize the AP-1 site on its own has been attributed to an inability to homodimerize (Kouzarides and Ziff 1988; Ransone et al. 1989; Turner and Tjian 1989|. The demonstration that Fos could homodimerize when its leucine repeat was replaced with that of GCN4 and that this chimeric molecule could recognize the AP-1 site on its own (Kouzarides and Ziff 1989; Sellers and Struhl 1989) supported the contention that amino acids preventing Fos from dimerizing are probably in the leucine repeat or near the repeat, but the precise residues are as yet unidentified. We speculate that dFRA recognizes the AP-1 site on its own by virtue of an inherent potential to form homodimers.

One suggestion as to why Fos does not bind the AP-1 site on its own is that Fos has few hydrophobic residues within its leucine repeat domain (O'Shea et al. 1989; Ransone et al. 1989). The high degree of hydrophobicity within the Jun dimerization domain, specifically in residues that comprise the 4-3 repeat lusing the nomenclature for coiled coils; O'Shea et al. 1989 and references therein), would account for its ability to form stable homo- as well as heterodimers. In this regard, it is interesting to note that dFRA contains a valine where Fos contains a threonine residue, and dFRA contains a glycine where Fos contains a lysine residue (Fig. 1C). Thus, it is possible that these residues in dFRA, which may contribute to the hydrophobicity along one face of the putative $\alpha$-helix, may contribute to homodimerization. Furthermore, it is also possible that dFRA possesses sequences in remaining portions of the molecule that would permit dimerization. A systematic mutagenesis of dFRA should provide information concerning the structural features of a Fos-related antigen that determine its ability to act autonomously.

Although dFRA binds the AP-1 site in the absence of dIRA, we observe that the apparent affinity of dFRA for the AP-1 site is weaker than that of dJRA. In some ex- 
periments, we have observed that more AP-1 oligonucleotide is complexed with dFRA at temperatures below $20^{\circ} \mathrm{C}$, whereas the formation of dJRA-AP- 1 site complexes is not as temperature-dependent. From these observations, we speculate that the temperature dependence of the dFRA-DNA complex suggests that this complex is not as stable as the dJRA-DNA complex. It is unclear how this complex stability affects transcription, as both proteins activate transcription in reactions carried out at $21^{\circ} \mathrm{C}$. However, there are other proteins in the transcription reaction that are likely to stabilize transcription complexes.

\section{Drosophila AP-1 family}

The isolation of dFRA and dJRA cDNAs from Drosophila opens an alternative pathway to understanding the functions of Fos and Jun proto-oncogenes in development. It is possible that dFRA and dJRA are the only AP-1 family members in Drosophila, because we did not detect any additional AP-1 cDNAs in our library screens, nor did we detect any additional AP-1 bindingsite activity during protein purification. In addition to Drosophila, members of the AP-1 family have now been isolated from such diverse species as yeast (Hope and Struhl 1985; Jones et al. 1988), humans (Bohmann et al. 1987), and plants (Katagiri et al. 1989) that are involved in a number of distinct cellular activities ranging from amino acid biosynthesis (Hope and Struhl 1985) to regulation of a fat-specific gene (Distel et al. 1987).

Other than the basic region and leucine repeat motifs, AP-1 family members bear few similar amino acid sequences. Jun is known to possess a transcriptional activation domain that is rich in prolines and acidic amino acids (Bohmann and Tjian 1989), and the transcriptional activation domain of GCN4 is highly acidic (Hope and Struhl 1985). Thus, we might have expected that dJRA (or dFRA) would contain a similar identifiable transcriptional activation domain. However, neither of the Drosophila AP-1 proteins appears to possess significant sequences in common with Fos and Jun outside of the conserved DNA-binding and dimerization domains. This finding is in keeping with the structures of many other AP-1 proteins. For example, the fra-1 cDNA that encodes a FRA from rat fibroblasts contains amino acids that are $77 \%$ conserved with the leucine repeat and basic domains of Fos but bears no similarity elsewhere in the molecule (Cohen and Curran 1988). In addition, the yeast AP-1 cDNA (yAP-1), which has been reported to encode a protein related to Jun, is structurally conserved only within the leucine repeat and basic domains (Moye-Rowley et al. 1989). Thus, these two sequence motifs have been conserved throughout evolution and confer on AP-1 proteins the ability to participate in diverse cellular pathways while using similar biochemical mechanisms.

\section{Materials and methods}

Purification of AFRA and dJRA and peptide sequencing

dFRA and dJRA proteins ( $\sim 3 \mu \mathrm{g}$ of each protein) were purified from Drosophila embryo extracts by sequence-specific DNA affinity chromatography and separated by reverse-phase high-performance liquid chromatography (HPLC), as described previously (Perkins et al. 1988), except that cysteine residues were alkylated with $1 \mathrm{M}$ 4-vinylpyridine in isopropanol for $2 \mathrm{hr}$ at $37^{\circ} \mathrm{C}$ immediately prior to HPLC injection. Following HPLC, dFRA and dJRA proteins [which elute from the column with $\sim 59 \%$ and $50 \%$ acetonitrile in $0.1 \%$ trifluoroacetic acid (TFA), respectively] were lyophilized to dryness. The pellets were resuspended in $100 \mathrm{mM}$ ammonium bicarbonate $(100 \mu \mathrm{l})$ and incubated with trypsin (40 ng) for $12-16 \mathrm{hr}$ at $37^{\circ} \mathrm{C}$. To separate the resulting peptides, the entire fraction was applied directly

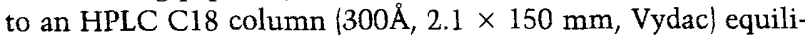
brated previously with $0.1 \%$ TFA. The peptides were eluted with a linear gradient of acetonitrile and sequenced by use of the Applied Biosystems Protein Sequencer 477A.

\section{Isolation of a recombinant clone encoding $A F R A$}

Two oligonucleotides (1, 5'-CCGGTGGGGATICCCATICCCAGIACGTCGATGGCGTTGGGCAGIAC-3') and 2, 5' -AAGGAGATCGAGGTICTGACCAACTCCAAG- ${ }^{\prime}$ were deduced from the amino acid sequences of two tryptic peptides $(1$, VLPNAIDVLGMGIPTGVS and 2, KGIEVLTNS) of dFRA by use of a Drosophila codon usage table (Lathe 1985; Streck et al. 1986). The oligonucleotides were labeled at the $5^{\prime}$ end with $\left[\gamma^{-32} \mathrm{P}\right]$ ATP and polynucleotide kinase and used to screen a cDNA library in $\lambda$ gtll prepared from Drosophila embryos between 9 and $12 \mathrm{hr}$ of development (kindly provided by K. Zinn). For this purpose, $\sim 700,000 \lambda$ plaques were plated at a density of 50,000 plaques per plate $(150 \times 20 \mathrm{~mm})$ and then transferred to nitrocellulose. The filters were hybridized with radioactive probes, in $5 \times$ Denhardt's $/ 50 \mathrm{mM} \mathrm{NaPO}{ }_{4}(\mathrm{pH} 6.8), 6 \times \mathrm{SSC}$ at $37^{\circ} \mathrm{C}$ for $16 \mathrm{hr}$ and then washed at $65^{\circ} \mathrm{C}$ (oligo 1) or at $50^{\circ} \mathrm{C}$ (oligo 2) in $2 \times \mathrm{SST} / 0.5 \%$ SDS. A single dFRA cDNA was isolated by this method.

\section{Isolation of recombinant clones encoding $\operatorname{dIRA}$}

Two oligonucleotides $(3,5$-CTTIACGATIGAGGCCAGGTCIACGTTCTCICCCTTCAG-3', and 4, 5'-ICCGAAGTCCAGCTGCTCIACGGTIACGGGICCGGC-3') were deduced from peptide sequences (3, LKGENVDLASIVK, and 4, AGPVTVEQLDFG) and labeled as described for dFRA. These oligonucleotides were then used to screen a Drosophila genomic library in $\lambda$ gt 10 (kindly provided by K. Moses). For this purpose, $\sim 40,000$ phage plaques were plated at a density of 20,000 plaques per plate $(150 \times 20 \mathrm{~mm})$, transferred to nitrocellulose, and hybridized with radioactive oligonucleotides $(3$ and $4 \mid$ by use of conditions described for dFRA. The filters were then washed at either $56^{\circ} \mathrm{C}$ (oligo 3) or $60^{\circ} \mathrm{C}$ (oligo 4) in buffers described for dFRA. Eleven positively hybridizing plaques were visualized by autoradiography and further purified. $\lambda$ DNA was prepared, digested with RsaI, HaeIII, and AluI, and subcloned into Ml3 to confirm the identities of these clones by DNA sequencing (Sanger et al. 1977). Six of these clones contained the sequences of the oligonucleotides for screening.

To obtain the dJRA cDNA clone, one of the genomic dJRA cDNA fragments in M13 was then used as a probe to screen a cDNA library prepared from Drosophila embryos between 3 and $12 \mathrm{hr}$ of development (kindly provided by L. Kauvar). To label the dJRA genomic insert in M13, single-stranded DNA was prepared and annealed to the universal M13 primer. Labeled DNA was synthesized in the presence of $\left[\alpha^{-32} \mathrm{P}\right] \mathrm{dCTP}$ and the Klenow fragment of $E$. coli DNA polymerase I. The DNA was then digested with EcoRI, and the labeled cDNA fragment 
was purified by $5 \%$ polyacrylamide gel electrophoresis. This labeled probe was used to screen the cDNA library by the same method described for dFRA, except that the wash was carried out at $65^{\circ} \mathrm{C}$. Two cDNA clones were obtained. Restriction enzyme analysis indicated that the two cDNAs were related. The longest of the two was analyzed further by DNA sequencing.

\section{Sequencing of IFRA and dJRA cDNAs}

To sequence the dFRA and dJRA cDNAs, $\lambda$ DNA containing the cDNAs was prepared, and the cDNA inserts were removed by digestion with EcoRI and subcloned into pBluescript-SK (Stratagene) to create dFRA-SK and dJRA-SK. Nested deletions in the cDNAs were then prepared by the method of Henikoff (1987), except that $\alpha$-thio-dNTPs (Stratagene) were used to prevent bidirectional exonuclease III digestion. Deletion mutants containing overlapping segments of the cDNAs were sequenced (Sanger et al. 1977) by use of the M13 universal primer.

\section{Expression of dFRA and dJRA in E. coli}

To create constructs that would express dFRA and dJRA proteins, NdeI sites were introduced at the initiating ATG codons in dFRA-SK and dJRA-SK by oligonucleotide-directed mutagenesis (Kunkel 1985). This resulted in the fortuitous introduction of a second NdeI site immediately downstream of the dIRA ORF. An NdeI site is present downstream of the wild-type dFRA ORF. By digestion of these constructs with NdeI, the cDNAs were removed. They were then subcloned into a unique NdeI site downstream from the $\phi 10$ promoter for T7 RNA polymerase in bacterial expression vector pAR3040 (Rosenberg et al. 1987). These constructs (dJRA-3040 and dFRA-3040) were used to transform E. coli strain BL21, which contains a chromosomal copy of the T7 RNA polymerase gene. Induction of the gene encoding $\mathrm{T} 7$ polymerase was induced by the method of Studier and Moffatt (1986).

\section{Purification of dFRA and dIRA from E. coli extracts}

Extracts $(5 \mathrm{ml}, \sim 15 \mathrm{mg}$ of protein $/ \mathrm{ml})$ were prepared as described (Hoey and Levine 1988) from E. coli (500 ml) harboring the dAP-1 cDNAs, except that the buffer used was $25 \mathrm{~mm}$ HEPES-KOH ( $\mathrm{pH} 7.6$ ), $0.1 \mathrm{~mm}$ EDTA, $12.5 \mathrm{~mm} \mathrm{MgCl}_{2}, 10 \%$ (vol/vol) glycerol, $0.1 \mathrm{M} \mathrm{KCl} \mathrm{(0.1} \mathrm{M} \mathrm{HEMG),} \mathrm{and} \mathrm{dFRA} \mathrm{and} \mathrm{dIRA}$ were fractionated in the supernatant of the $35 \mathrm{~K}$ centrifugation. The salt concentration of the supernatant was adjusted to $0.3 \mathrm{M}$ $\mathrm{KCl}$ and was applied to a DEAE-Sepharose CL-6B (Pharmacia) column $(1 \mathrm{ml})$ that had been equilibrated previously with $0.3 \mathrm{M}$ HEMG. Then the column was washed with three volumes of $0.3 \mathrm{M}$ HEMG. The flowthrough $(5.4 \mathrm{ml}, \sim 10 \mathrm{mg}$ of protein $/ \mathrm{ml})$ and wash $(3 \mathrm{ml}, \sim 3 \mathrm{mg}$ of protein $/ \mathrm{ml})$ were pooled, and either $16 \mu \mathrm{g}$ (for dFRA) or $156 \mu \mathrm{g}$ (for dJRA) of poly[d(I-C)] was added. The conductivity was adjusted to $0.1 \mathrm{M}$ HEMG by the addition of HEMG, and the fractions $(24 \mathrm{ml})$ were applied to DNA affinity columns $(0.5 \mathrm{ml})$ containing an AP-1 recognition site oligonucleotide (Perkins et al. 1988). The columns were washed with 5 column volumes of $0.1 \mathrm{M}$ HEMG and eluted stepwise with 3 volumes of $0.2 \mathrm{M} \mathrm{HEMG}, 2$ volumes of $0.5 \mathrm{M} \mathrm{HEMG}$, and 3 volumes of $1 \mathrm{M}$ HEMG. Fractions were analyzed by SDSPAGE. We estimate that from $500 \mathrm{ml}$ of $E$. coli $\left(\mathrm{OD}_{600}=0.6-\right.$ 0.8 , we obtain $\sim 9 \mu \mathrm{g}$ of dJRA and $5 \mu \mathrm{g}$ of dFRA protein.

\section{In vitro translation of dFRA and IIRA and mobility-shift analysis}

For transcription and translation in vitro, the cDNAs in dFRA-3040 or dJRA-3040 were excised with NdeI, digested with mung bean exonuclease (Stratagene), and subcloned into the StuI site of pBSal (Norman et al. 1988). Transcription and translation in vitro, as well as mobility-shift analyses, were conducted as described (Turner and Tjian 1989) except that the DNA-binding reactions and gel electrophoresis were carried out at $4^{\circ} \mathrm{C}$. In cotranslation experiments with dFRA and dJRA, the amount of RNA from each cDNA was one-half the amount used when these proteins were translated individually.

\section{Nonradioactive in situ hybridization experiments}

For nonradioactive in situ hybridization experiments, singlestranded DNA probes were synthesized from the dFRA cDNA by the polymerase chain reaction in the presence of digoxigenin-labeled dUTP (Boehringer-Mannheim; N.H. Patel and C.S. Goodman, unpubl.). Hybridization and detection were carried out by use of the protocols of Tautz and Pfeifle (1989) and the Boehringer-Mannheim Genius kit. This nonradioactive procedure provides a much finer level of resolution than radioactive probes and allows for expressing cells to be located in intact embryos instead of tissue sections. The specificities of these signals and the signals observed by using radioactive probes were confirmed by hybridization with probes to the opposite DNA strand (data not shown).

\section{Acknowledgments}

We acknowledge Willy Liao, Myung Shin, Gina Dailey, and Bobbi Johnson for their technical support. We thank Corey Goodman and Gerry Rubin and many people from their labs and from the Tjian lab for helpful discussions and technical expertise, especially Matthew Freeman, Hilary Clark, and Todd Laverty for the in situ hybridization experiments. We extend special thanks to Sharyn Endow and her laboratory for providing chromosomal DNA from the 99B $(9-10)$ locus and for many helpful conversations. We appreciate the critical reading of this manuscript by Vijay Baichwal, Richard Turner, and Al Courey. We are also grateful to Karen Ronan for typing this manuscript and preparation of the figures. K.P. is supported by a grant from the Damon Runyon-Walter Winchell Cancer Research Fund (DRG-931).

\section{References}

Adamson, E.D. 1987. Oncogenes in development. Development 99: 449-471.

Bender, W. and M. Peifer. 1987. Oncogenes take wing. Cell 50: $519-520$.

Bishop, J.G. III and V.G. Corces. 1988. Expression of an activated ras gene causes developmental abnormalities in transgenic Drosophila melanogaster. Genes Dev. 2: 567-577.

Bodmer, R., S. Barbel, S. Sheperd, J.W. Jack, L.Y. Jan, and Y.-N. Jan. 1987. Transformation of sensory organs by mutations of the cut locus of D. melanogaster. Cell 51: 293-307.

Bohmann, D. and R. Tjian. 1989. Biochemical analysis of transcriptional activation by Jun: Differential activity of c- and v-jun. Cell 59: 709-711.

Bohmann, D., T.J. Bos, A. Admon, T. Nishimura, P.K. Vogt, and R. Tjian. 1987. Human proto-oncogene c-Jun encodes a DNA binding protein with structural and functional properties of transcription factor AP-1. Science 238: 1386-1392.

Chiu, R., W.J. Boyle, J. Meek, T. Smeal, T. Hunter, and M. Karin. 1988. The c-Fos protein interacts with c-Jun/AP-1 to stimulate transcription of $\mathrm{AP}-1$ responsive genes. Cell 54: $541-552$.

Cohen, D.R., and T. Curran. 1988. fra-1: A serum-inducible, 
cellular immediate early gene that encodes a fos-related antigen. Mol. Cell. Biol. 8: 2063-2069.

Curran, T. and B.R. Franza, Jr. 1988. Fos and Jun: The AP-1 connection. Cell 55: 395-397.

Curran, T. and N.M. Teich. 1982. Candidate product of the FBJ murine osteosarcoma virus oncogene: Characterization of a 55,000-dalton phosphoprotein. J. Virol. 42: 114-122.

Deschamps, J., R.L. Mitchell, F. Meijlink, W. Kruijer, D. Schubert, and I.M. Verma. 1985. Proto-oncogene fos is expressed during development, differentiation, and growth. Cold Spring Harbor Symp. Quant. Biol. 50: 733-745.

Distel, R.J., H.-S. Ro, B.S. Rosen, D.L. Groves, and B.M. Spiegelman. 1987. Nucleoprotein complexes that regulate gene expression in adipocyte differentiation: Direct participation of c-fos. Cell 49: 835-844.

Dynlacht, B.D., L.D. Attardi, A. Admon, M. Freeman, and R. Tiian. 1989. Functional analysis of NTF-1, a developmentally regulated Drosophila transcription factor that binds neuronal cis elements. Genes Dev. 3: 1677-1688.

Gentz, R., F.J. Rauscher, III, C. Abate, and T. Curran. 1989. Parallel association of Fos and Jun leucine zippers juxtaposes DNA binding domains. Science 243: 1695-1699.

Ghysen, A., C. Dambly-Chaudiere, E. Aceves, L.-Y. Jan, and Y.-N. Jan. 1986. Sensory neurons and peripheral pathways in Drosophila embryos. Wilhelm Roux's Arch. Dev. Biol. 195: 281-289.

Halazonetis, T.D., K. Georgopoulos, M.E. Greenberg, and P. Leder. 1988. c-Jun dimerizes with itself and with c-Fos, forming complexes of different DNA binding affinities. Cell 55: $917-924$.

Hanley, M.R. 1988. Proto-oncogenes in the nervous system. Neuron 1: 175-182.

Hauser, C.A., A.L. Joyner, R.D. Klein, T.K. Learned, G.R. Martin, and R. Tjian. 1985. Expression of homologous homeobox-containing genes in differentiated human teratocarcinoma cells and mouse embryos. Genes Dev. 43: 19-28.

Heberlein, U., B. England, and R. Tjian. 1985. Characterization of Drosophila transcription factors that activate the tandem promoters of the alcohol dehydrogenase gene. Cell 41: 965977.

Henikoff, S. 1987. Unidirectional digestion with exonuclease III in DNA sequence analysis. Methods Enzymol. 155: 156165.

Hoey, T. and M. Levine. 1988. Divergent homeobox proteins recognize similar DNA sequences in Drosophila. Nature 332: 858-861.

Hope, I.A. and K. Struhl. 1985. GCN4 protein, synthesized in vitro, binds HIS 3 regulatory sequences: Implications for general control of amino acid biosynthetic genes in yeast. Cell 43: 177-189.

Jones, R.H., S. Moreno, P. Nurse, and N.C. Jones. 1988. Expression of the SV40 promoter in fission yeast: Identification and characterization of an AP-1-like factor. Cell 53: 659667.

Katagiri, F., E. Lam, and N.-H. Chua. 1989. Two tobacco DNAbinding proteins with homology to the nuclear factor, CREB. Nature 340: 727-729.

Kunkel, T.A. 1985. Rapid and efficient site-specific mutagenesis without phenotype selection. Proc. Natl. Acad. Sci. 82: $488-492$.

Kouzarides, T. and E. Ziff. 1988. The role of the leucine zipper in the Fos-Jun interaction. Nature 366: 646-651.

-. 1989. Leucine zippers of fos, jun and GCN4 dictate dimerization specificity and thereby control DNA binding. Nature 340: 568-571.

Landschulz, W.H., P.F. Johnson, and S.L. McKnight. 1988. The leucine zipper: A hypothetical structure common to a new class of DNA binding proteins. Science 240: 1759-1764.

Lathe, R. 1985. Synthetic oligonucleotide probes deduced from amino acid sequence data: Theoretical and practical considerations. J. Mol. Biol. 183: 1-12.

Lee, W., P. Mitchell, and R. Tjian. 1987. Purified transcription factor AP-1 interacts with TPA-inducible enhancer elements. Cell 49: 741-752.

Morgan, J.I., D.R. Cohen, H.L. Hempstead, and T. Curran. 1987. Mapping patterns of $\mathrm{c}$-fos expression in the central nervous system after seizure. Science 237: 192-197.

Moye-Rowley, W.S., K.D. Harshman, and C.S. Parker. 1989. Yeast YAP1 encodes a novel form of the jun family of transcriptional activator proteins. Genes Dev. 3: 283-292.

Nakabeppu, Y., K. Ryder, and D. Nathans. 1988. DNA binding properties of three murine Jun proteins: Stimulation by Fos. Cell 55: 907-915.

Norman, C., M. Runswick. R. Pollock, and R. Treisman. 1988. Isolation and properties of cDNA clones encoding SRF, a transcription factor that binds to the $\mathrm{c}$-fos serum response element. Cell 55: 989-1003.

O'Shea, E.K., R. Rutkowski, W.F. Stafford, III, and P.S. Kim. 1989. Preferential heterodimer formation by isolated leucine zippers from Fos and Jun. Science 245: 646-648.

Patel, N.H., B. Schafer, C.S. Goodman, and R. Holmgren. 1989. The role of segment polarity genes during Drosophila neurogenesis. Genes Dev. 3: 890-904.

Perkins, K.K., G.M. Dailey, and R.T. Tjian. 1988. Novel Fosand Jun-related proteins in Drosophila are functionally homologous to enhancer factor AP-1. EMBO $/$. $7\{13\}: 4265-$ 4273.

Ransone, L.J., J. Visvader, P. Sassone-Corsi, and I. Verma. 1989. Fos-Jun interaction: mutational analysis of the leucine zipper domain of both proteins. Genes Dev. 3: 770-781.

Rauscher, F.J. III, P.J. Voulalas, B.R. Franza, Jr., and T. Curran. 1988a. Fos and Jun bind cooperatively to the AP-1 site: reconstitution in vitro. Genes Dev. 2: 1687-1699.

Rauscher, F.J. III, D.R. Cohen, T. Curran, T.J. Bos, P.K. Vogt, D. Bohmann, R. Tjian, and B.R. Franza, Jr. 1988b. Fos-associated protein p39 is the product of the Jun-proto-oncogene. Science 240: 1010-1016.

Rosenberg, A.H., B.N. Lade, D. Chui, S.-W. Lin, J.J. Dunn, and F.W. Studier. 1987. Vectors for selective expression of cloned DNAs by T7 RNA polymerase. Gene 56: 125-135.

Ryder, K., L.F. Lau, and D. Nathans. 1989. A gene activated by growth factors is related to the oncogene v-jun. Proc. Natl. Acad. Sci. 85: 1487-1491.

Saffen, D.W., A.J. Cole, P.F. Worley, B.A. Christy, K. Ryder, and J.M. Baraban. 1988. Convulsant-induced increase in transcription factor mRNAs in rat brain. Proc. Natl. Acad. Sci. 85: 7795-7799.

Sanger, F., S. Nicklen, and A.R. Coulson. 1977. DNA sequencing with chain-terminating inhibitors. Proc. Natl. Acad. Sci. 74: 5463-5467.

Sassone-Corsi, P., L.J. Ransone, W.W. Lamph, and I.M. Verma. 1988. Direct interaction between fos and jun nuclear oncoproteins: Role of the "leucine zipper" domain. Nature 336: 692-695.

Schejter, E.D. and B-Z. Shilo. 1989. The Drosophila EGF receptor homolog (DER) gene is allelic to faint little ball, a locus essential for embryonic development. Cell 56: 10931104.

Schønthal, A., P. Herrlich, H.J. Rahmsdorf, and H. Ponta. 1988. Requirement for fos gene expression in the transcriptional activation of collagenase by other oncogenes and phorbol esters. Cell 54: 325-334. 
Perkins et al.

Schuermann, M., M. Neuberg, J.B. Hunter, T. Jenuwein, R.-P. Ryseck, R. Bravo, and R. Müller. 1989. The leucine repeat motif in Fos protein mediates complex formation with Jun/ AP- 1 and is required for transformation. Cell 56: 507-516.

Sellers, J.W. and K. Struhl. 1989. Changing Fos oncoprotein to a Jun-independent DNA-binding protein with GCN4 dimerization specificity by swapping "leucine zippers." Nature 341: 74-76.

Shilo, B.-Z. 1987. Proto-oncogenes in Drosophila melanogaster. Trends Genet. 3: 69-72.

Steward, R. 1987. Dorsal, an embryonic polarity gene in Drosophila, is homologous to the vertebrate proto-oncogene, c-rel. Science 238: 692-694.

Streck, R.D., J.E. MacGaffey, and S.K. Beckendorf. 1986. The structure of hobo transposable elements and their insertion sites. EMBO I. 5: 3615-3623.

Studier, J.W. and B.A. Moffatt. 1986. Use of bacteriophage T7 RNA polymerase to direct selective high-level expression of cloned genes. I. Mol. Biol. 189: 113-130.

Tautz, D. and C. Pfeifle. 1989. A non-radioactive in situ hybridization method for the localization of specific RNAs in Drosophila embryos reveals translational control of the segmentation gene hunchback. Chromosoma 98: 81-85.

Turner, R., and R. Tjian. 1989. Leucine repeats and an adjacent DNA binding domain mediate the formation of functional c-Fos-c-Jun heterodimers. Science 243: 1689-1694.

Wilkinson, D.G., S. Bhatt, R.-P. Ryseck, and R. Bravo. 1989. Tissue-specific expression of c-jun and jun $B$ during organogenesis in the mouse. Development 106: 465-471.

Yamamoto, A.H., D.J. Komma, C.D. Shaffer, V. Pirotta, and S.A. Endow. 1989. The claret locus in Drosophila encodes products required for eye color and for meiotic chromosome segregation. EMBO I. 8: 3543-3552.

Zerial, M., L. Toschi, R.P. Ryseck, M. Schuermann, R. Müller, and R. Bravo. 1989. The product of a novel growth factor activated gene, $f O s B$, interacts with JUN proteins enhancing their DNA binding activity. EMBO I. 8: 805-819. 


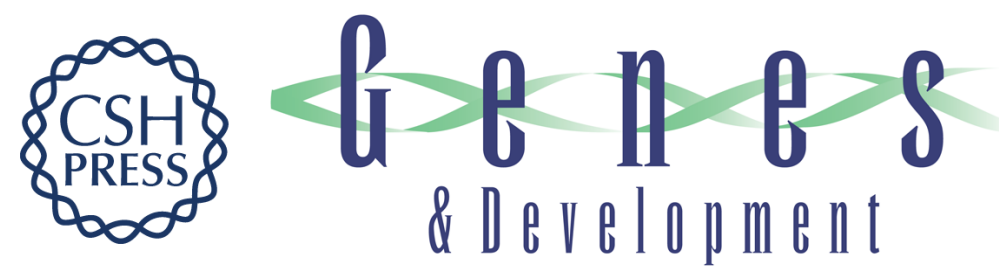

\section{The Drosophila Fos-related AP-1 protein is a developmentally regulated transcription factor.}

K K Perkins, A Admon, N Patel, et al.

Genes Dev. 1990, 4:

Access the most recent version at doi:10.1101/gad.4.5.822

References This article cites 58 articles, 22 of which can be accessed free at:

http://genesdev.cshlp.org/content/4/5/822.full.html\#ref-list-1

License

Email Alerting Receive free email alerts when new articles cite this article - sign up in the box at the top Service right corner of the article or click here.

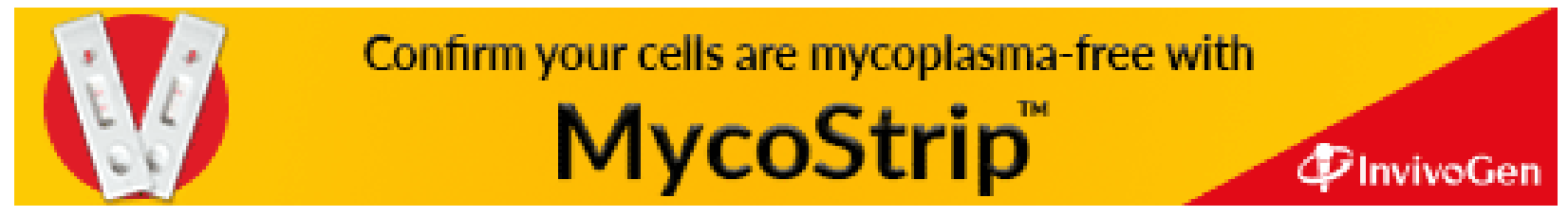

